\title{
Interfacial Nucleation in iPP/PB-1 Blends Promotes the Formation of Polybutene-1 Trigonal Crystals
}

Zefan Wang ${ }^{1,2}$, Xia Dong ${ }^{1,2}$, Guoming Liu ${ }^{1}$, Qian Xing ${ }^{3}$, Dario Cavallo ${ }^{4}$, Qianhong Jiang, ${ }^{1,2}$ Alejandro J. Müller ${ }^{5,6}$, Dujin Wang ${ }^{1,2} *$

${ }^{1}$ CAS Key Laboratory of Engineering Plastics, CAS Research/Education Center for Excellence in Molecular Sciences, Institute of Chemistry, Chinese Academy of Sciences, Beijing 100190, China

${ }^{2}$ University of Chinese Academy of Sciences, Beijing 100049, China

${ }^{3}$ School of Materials Science and Mechanical Engineering, Beijing Technology and Business University, Beijing 100048, China

${ }^{4}$ Department of Chemistry and Industrial Chemistry, University of Genova, via Dodecaneso, 31 - 16146 Genova, Italy

${ }^{5}$ POLYMAT and Polymer Science and Technology Department, Faculty of Chemistry, University of the Basque Country UPV/EHU, Paseo Manuel de Lardizabal 3, 20018 Donostia-San Sebastián, Spain

${ }^{6}$ Ikerbasque, Basque Foundation for Science, Bilbao, Spain

*Corresponding authors: djwang@iccas.ac.cn and alejandrojesus.muller@ehu.eus 


\section{ABSTRACT}

The formation of trigonal Form I' crystals of polybutene-1 (PB-1) directly from melt has drawn much attention in past decades. In this study, we investigate the fractionated crystallization behavior of PB-1 within microdomains formed by blending PB-1 with an excess of isotactic polypropylene (iPP) employing DSC, SEM, in situ synchrotron WAXD and FTIR. When PB-1 is dispersed into a large number of small size droplets, the heterogeneous nucleation of Form II crystals can be inhibited because the number of droplets is larger than that of active nucleation sites for Form II (i.e., active heterogeneities originally present in bulk PB-1). The crystallization rate of Form I' at different temperatures was determined by Fourier transform infrared spectroscopy. It was found that trigonal Form I' crystallizes faster when the content of PB-1 in the blend is lower, and the specific interfacial surface area is larger. The opposite effect has been observed for the kinetics of the metastable Form II formation. It is therefore suggested that Form $\mathrm{I}^{\prime}$ crystallization is driven by the nucleation of PB-1 at the crystalline iPP surface, which competes with the crystallization of Form II induced by nucleating heterogeneities present in PB-1 droplets.

Keywords: Polybutene-1; Form I'; crystallization; fractionated crystallization; interfacial nucleation 


\section{INTRODUCTION}

Semicrystalline polymers can show various nucleation paths depending on crystallization conditions and dispersion state. Two main types of nucleation, i.e., heterogeneous and homogeneous, are generally recognized. ${ }^{1-3}$ Most polymers contain heterogeneities that can account for triggering nucleation at relatively low supercoolings, when polymers are cooled from the melt. The energy barrier for heterogeneous nucleation is smaller than that associated with the creation of homogeneous nuclei by spontaneous chain assembly, therefore, most polymers in the bulk state only undergo heterogeneous nucleation.

However, the crystallization ability of polymers can significantly change when they are dispersed in microdomains (MDs). ${ }^{4,5}$ In this case, fractionated crystallization or a large depression in crystallization temperature can occur. In fact, bulk polymers normally crystallize from the melt in a relatively narrow crystallization temperature range as reflected by a single exothermic peak during a DSC cooling run. However, when the same polymer is dispersed into fine droplets in an immiscible matrix, several crystallization peaks can arise during cooling from the melt, which is interpreted as the "fractionated" crystallization of different crystal populations nucleated at distinct supercoolings. Fractionated crystallization usually occurs when the number of MDs is comparable to the number of nucleating heterogeneities originally present in the bulk sample. During polymer blending, several populations of droplets are generated, which can be free of any heterogeneity or contain the different types of them. When the number of MDs is much larger than that of active heterogeneities, only one exothermic peak appears at a very large supercooling. In this case, clean droplets have been generated by blending that can be homogeneously nucleated, or nucleated at the interface with the second polymer. ${ }^{6}$

In recent years, a variety of methods have been proposed to create confined environments, including the synthesis of block copolymers, ${ }^{7-15}$ dewetting the polymer melt into droplets, ${ }^{16,17}$ and infiltration of polymeric samples within anodic aluminum oxide (AAO) templates. ${ }^{2,}{ }^{18-21}$ However, blending immiscible polymeric materials 
remains an easy and convenient way to obtain droplet dispersions. ${ }^{2,6,22,23}$

The size and distribution of the MDs strongly depend on the composition of the immiscible blends and the blending strategy. Typically, fractionated crystallization will occur when the amount of dispersed phase is small enough (30 wt $\%$ or less)., ${ }^{2,3}$ Many systems have been studied in the past several decades, for instance polyamide 6/poly (vinylidene fluoride), ${ }^{4}$ poly (butylene terephthalate)/poly(vinylidene fluoride), poly(3-hydroxybutyrate)/poly(ethylene oxide) ${ }^{24}$ polyamide 6/polypropylene, ${ }^{25}$ polyolefins/polyamide $6,{ }^{26}$ and polystyrene/polyamide $6 .^{27-30}$

Arnal et al. ${ }^{6}$ systematically studied the fractionated crystallization process of isotactic polypropylene (iPP) blended with polystyrene (PS) and found up to four exothermic peaks corresponding to the iPP droplets, which were attributed to the distribution of different types of active heterogeneities in different MDs together with the nucleation of the supposedly clean droplets at maximum supercooling. The addition of a compatibilizing agent could reduce the droplet size (while vastly increasing their number), thus leading to a single crystallization exotherm at extremely large supercooling, that was attributed to the nucleation and crystallization of clean droplets. On the other hand, if the iPP droplets were self-nucleated, active self-seeds could be injected into every droplet with the total disappearance of the fractionated crystallization and the crystallization of iPP in a single exotherm located at very low supercoolings.

Tol et al. ${ }^{27}$ found that polyamide 6 could crystallize into different polymorphs if it was dispersed as small sized droplets blended with PS, e.g., the stable $\gamma$ form of polyamide 6 could be formed when the size of MDs decreased to 1-10 $\mu \mathrm{m}$.

Isotactic polybutene-1 (PB-1) is a well-known polyolefin, characterized by a complex polymorphic behavior. ${ }^{31,32}$ There are at least four crystal modifications (Forms I, I', II and III) with different chain conformations. ${ }^{33-37}$ Form I is a trigonal structure with $3_{1}$ helices and maximum thermodynamic stability, and is normally obtained by a spontaneous slow transition from Form II, which occurs in the solid state also at room temperature. ${ }^{38,39}$ The metastable Form II (tetragonal) with $11_{3}$ helices is normally obtained by cooling from the melt. In addition, Form I' shows the 
same crystal structure as Form I, but has a lower melting temperature (90-100 $\left.{ }^{\circ} \mathrm{C}\right)$. Obtaining Forms I and I' directly from the melt has attracted recent attention.

Cavallo et al. ${ }^{40-44}$ found that small amounts of Form $\mathrm{I}^{\prime}$ can be produced by self-nucleation (SN) inside Form I spherulites when the SN temperature is not very high. Ji and co-workers ${ }^{45}$ successfully obtained Form I' crystals by mixing PB-1 with an iPP of low tacticity. Zhang et al. ${ }^{46}$ reported that single crystals of Form I could be obtained by isothermal crystallization from the melt for 5 days in ultrathin films at 110 ${ }^{\circ} \mathrm{C}$. Shieh et al. ${ }^{47}$ indicated that Form I' crystals could be easily formed when PB-1 is blended with iPP, but the formation mechanism of Form I' was not investigated in-depth.

Therefore, the main aim of the present work is to systematically explore the crystallization behavior of PB-1 blended with iPP, to enlighten the crystallization mechanism of Form I' in small PB-1 droplets. It was found that Form II can be effectively suppressed when PB-1 is dispersed into small droplets within an iPP matrix, while Form I' can be generated during fractionated crystallization. These results indicate that the presence of iPP crystals at the PP/PB-1 blends interface plays an important role in the formation of Form I'.

\section{EXPERIMENTAL SECTION}

An isotactic polybutene-1 (trade name: PB0110M) with a weight average molecular weight of $6.4 \times 10^{5} \mathrm{~kg} / \mathrm{mol}$ was purchased from Lyondell Basell Industries. The iPP sample (trade name: S1003) with a weight average molecular weight of $4.0 \times$ $10^{5} \mathrm{~kg} / \mathrm{mol}$ was kindly supplied by SINOPEC Beijing Yanshan Company.

The pellets of iPP and PB-1 were melt blended at $200{ }^{\circ} \mathrm{C}$ using an internal mixer (Haake Rheomix OS) at a rotating speed of $50 \mathrm{rpm}$ for $5 \mathrm{~min}$. The PB-1 content in the blends was $10,20,25,30,35$, and $40 \mathrm{wt} \%$. Correspondingly, the blends were labeled as PP/PB 90/10, 80/20, 75/20, 70/30, 65/35, and 60/40, respectively. Neat iPP and PB-1 samples were subjected to the same treatment in the internal mixer for comparison. 
The morphology of the PP/PB-1 blends was observed with a JEOL JSM-6700F scanning electron microscope (SEM). Each sample was first melted at $250{ }^{\circ} \mathrm{C}$ for 5 min or $12 \mathrm{~h}$, the latter annealing performed in order to examine the miscibility between the two polymers, and then cooled down to room temperature at a rate of 10 ${ }^{\circ} \mathrm{C} / \mathrm{min}$. The prepared specimens were cryo-fractured by immersing in liquid nitrogen. Then the samples were etched by xylene at $60{ }^{\circ} \mathrm{C}$ for $15 \mathrm{~min}$ to better examine the size and distribution of MDs.

The thermal behavior of the samples was characterized by differential scanning calorimetry (DSC, Q2000, TA Instruments) under nitrogen atmosphere calibrated with indium. In the non-isothermal scans, the samples were first heated to $250{ }^{\circ} \mathrm{C}$ for $3 \mathrm{~min}$ to erase thermal history and then cooled to $30{ }^{\circ} \mathrm{C}$ at different rates $\left(0.5^{\circ} \mathrm{C} / \mathrm{min}\right.$ and 10 ${ }^{\circ} \mathrm{C} / \mathrm{min}$ ), followed by heating to the final temperature of $200{ }^{\circ} \mathrm{C}$ at $10{ }^{\circ} \mathrm{C} / \mathrm{min}$.

The isothermal crystallization was explored by the DSC thermal protocol shown in Figure 1a. All samples were first quenched from $250{ }^{\circ} \mathrm{C}$ to $125{ }^{\circ} \mathrm{C}$ at $30{ }^{\circ} \mathrm{C} / \mathrm{min}$ and held at $125{ }^{\circ} \mathrm{C}$ for $60 \mathrm{~min}$ to crystallize iPP completely, and then quenched to different temperatures $\left(65,70,75,80\right.$ and $\left.85{ }^{\circ} \mathrm{C}\right)$ for $3 \mathrm{~h}$ to guarantee complete crystallization of the blend samples, followed by heating to $200{ }^{\circ} \mathrm{C}$ directly.

The self-nucleation ( $\mathrm{SN}$ ) test was designed as shown in Figure 1b. The samples were heated to $250^{\circ} \mathrm{C}$ and kept for $3 \mathrm{~min}$ at this temperature to erase thermal history. Then the samples were cooled at $10{ }^{\circ} \mathrm{C} / \mathrm{min}$ down to $30{ }^{\circ} \mathrm{C}$, in order to provide a standard thermal history, followed by heating at $10{ }^{\circ} \mathrm{C} / \mathrm{min}$ up to the chosen $\mathrm{SN}$ temperature or $T_{s}$, where the sample was kept for $5 \mathrm{~min}$, and during this time period the samples were completely melted, self-nucleated or self-nucleated and annealed, depending on the value of $T_{s}$. The samples were then cooled at $10{ }^{\circ} \mathrm{C} / \mathrm{min}$ from $T s$ down to $30^{\circ} \mathrm{C}$. Finally, the samples were heated to $200{ }^{\circ} \mathrm{C}$. 

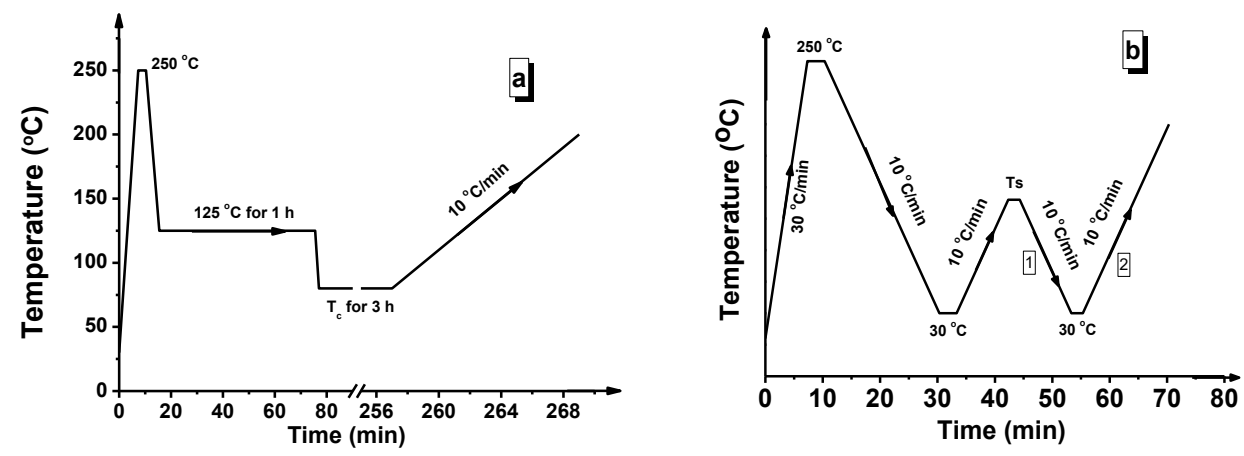

Figure 1. DSC thermal protocols applied for isothermal crystallization (a) and self-nucleation (b).

In situ synchrotron wide-angle X-ray diffraction (in-situ WAXD) experiments were performed at BL14B Beamline in Shanghai Synchrotron Radiation Facility (SSRF). Samples (80/20 and 70/30) were selected and wrapped with a piece of thin aluminum foil. Temperature control was applied with a Linkam 600 hot stage. The samples were first heated to $250{ }^{\circ} \mathrm{C}$ and kept for $3 \mathrm{~min}$ at that temperature to erase thermal history, and then cooled at a rate of $0.5{ }^{\circ} \mathrm{C} / \mathrm{min}$. WAXD patterns were collected during the cooling process. In order to avoid thermal degradation, all thermal treatments were carried out under $\mathrm{N}_{2}$ atmosphere. The distance between the samples and detector was $423.8 \mathrm{~mm}$ and the X-rays wavelength was $1.24 \AA$.

WAXD experiments were also carried out on a Xeuss 2.0 system of Xenocs (France) with a $\mathrm{Cu} \mathrm{K \alpha}$ source (wavelength $=1.54 \AA$ ) and a sample to detector distance of 140.2 mm. Scattering patterns were collected by a semiconductor detector (Pilatus $300 \mathrm{~K}$, DECTRIS, Swiss) with a resolution of $487 \times 619$ pixels (pixel size $=172 \mu \mathrm{m}^{2}$ ). Each WAXD pattern was collected for $15 \mathrm{~min}$ and the one-dimensional intensity profiles were integrated using the standard procedure after background subtraction.

Fourier transform infrared (FT-IR) spectra were recorded using a Nicolet 6700 spectrometer equipped with a Linkam FTIR600 hot stage. The samples were first heated to $250{ }^{\circ} \mathrm{C}$ for $5 \mathrm{~min}$, and then quenched to $125{ }^{\circ} \mathrm{C}$ and kept at this temperature for $60 \mathrm{~min}$, followed by rapidly cooling $\left(30{ }^{\circ} \mathrm{C} / \mathrm{min}\right)$ to differently isothermal crystallization temperatures $\left(85{ }^{\circ} \mathrm{C}\right.$ with a small amount of Form II crystals). FT-IR spectra with a resolution of $4.0 \mathrm{~cm}^{-1}$ and 16 scans were collected during the 
isothermal crystallization. All IR spectra were baseline corrected according to the same standard procedure. ${ }^{48}$

\section{RESULTS AND DISCUSSION}

\section{Phase separated morphology of the PP/PB-1 blends.}

It has been shown that the crystallization behavior of a semi-crystalline polymer changes when it is finely dispersed in the matrix of another polymer, ${ }^{2,3}$ therefore, it is very important to obtain the information on the miscibility of two components, as this will determine the morphology of the material.

The phase behavior of PP/PB-1 blends has been studied before, but there is no consensus in the literature so far. ${ }^{49}$ Bartczak et al. ${ }^{50}$ reported phase separation of iPP and PB-1 blends after thermal treatment at high temperature $\left(220{ }^{\circ} \mathrm{C}\right)$ or long time annealing, according to SEM observations. Ji et al. ${ }^{45}$ indicated that a low tacticity polypropylene/PB-1 blend prepared by solution mixing can separate into two phases at high temperatures during a short period of time, after which it merges into one.

It seems that the chain structure and molecular weight have an important influence on the miscibility of PP/PB-1 blend. In the present case, the PP/PB-1 blends always display phase separation even after annealing at $250{ }^{\circ} \mathrm{C}$ for $12 \mathrm{~h}$ (Figure S1). Similar results were summarized by White et al. ${ }^{51}$ in a review paper. They indicated that iPP and PB-1 are partially miscible and can separate into two phases below $250{ }^{\circ} \mathrm{C}$.

SEM micrographs of the PP/PB-1 blends with different content ratios are shown in Figure 2. The micrographs reveal a sea-island morphology, typical of immiscible blends. The immiscibility of the blends was also confirmed by the constant values of the melting points of both phases, which were independent of composition (see Figure 3 and its discussion below). The average number and volume diameter ( $d_{n}$ and $\left.d_{v}\right)$, dispersity $(D)$, volume fraction of dispersed phase $\left(X_{v}\right)$ and average particle number per $\mathrm{cm}^{3}\left(N_{i}\right)$ shown in Table 1 were calculated according to equations proposed in the literature, ${ }^{6}$ by measuring more than 100 particles. As the content of PB-1 in the blends increased from $10 \mathrm{wt} \%$ to $40 \mathrm{wt} \%$, the average size of droplets increased from 
$0.19 \mu \mathrm{m}$ to $15.45 \mu \mathrm{m}$, and the $N i$ value reduced from $2.80 \times 10^{14} / \mathrm{cm}^{3}$ to $2.08 \times$ $10^{8} / \mathrm{cm}^{3}$.
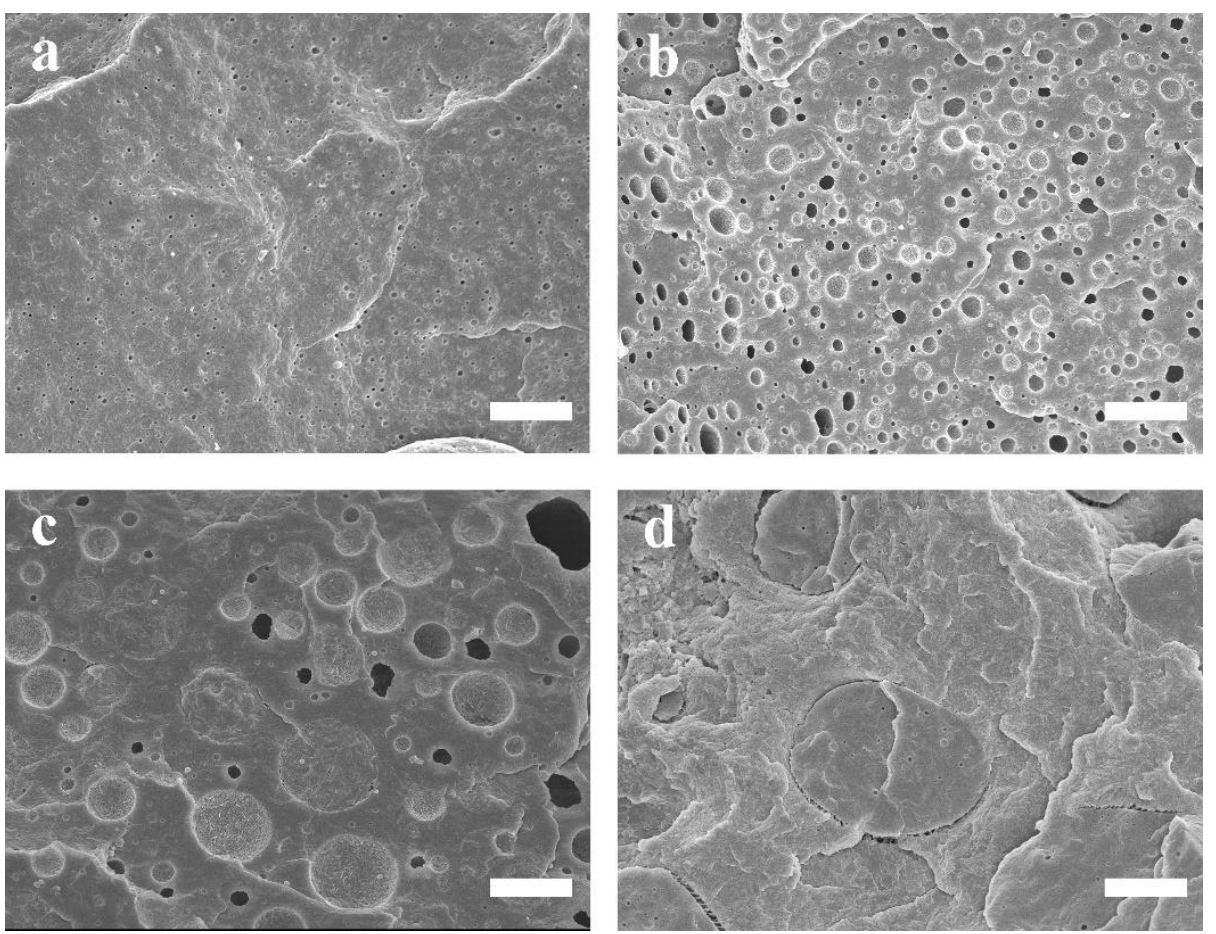

Figure 2. SEM micrographs of the PP/PB-1 blends: (a) 90/10, (b) 80/20, (c) 70/30, (d) 60/40. Scale bar: $5 \mu \mathrm{m}$.

Table 1. Morphological characterization of PP/PB-1 blends

\begin{tabular}{cccccc}
\hline PP/PB-1 & $d_{n}(\mu \mathrm{m})$ & $d_{v}(\mu \mathrm{m})$ & $D$ & $X_{v}$ & $N i\left(\mathrm{~cm}^{-3}\right)$ \\
\hline $90 / 10$ & 0.19 & 0.27 & 1.45 & 0.1005 & $2.80 \times 10^{14}$ \\
$80 / 20$ & 0.49 & 0.95 & 1.95 & 0.2004 & $3.18 \times 10^{12}$ \\
$70 / 30$ & 1.51 & 7.95 & 5.27 & 0.3012 & $1.46 \times 10^{11}$ \\
$60 / 40$ & 15.45 & 18.68 & 1.21 & 0.4013 & $2.08 \times 10^{8}$ \\
\hline
\end{tabular}

\section{Fractionated crystallization behavior: non-isothermal crystallization.}

Figure 3 shows the DSC cooling and heating curves of PP/PB-1 samples at 10 ${ }^{\circ} \mathrm{C} / \mathrm{min}$. The peak crystallization and melting temperatures of neat PB-1 are $76.5{ }^{\circ} \mathrm{C}$ and $116{ }^{\circ} \mathrm{C}$, corresponding to the crystallization and melting of PB-1 Form II, 
respectively.

The crystallization behavior of PB-1 significantly changes in the blends. In the case of PP/PB-1 60/40 and 65/35 blends, the exotherms around $115^{\circ} \mathrm{C}$ are due to the crystallization of the iPP matrix, while the PB-1 droplets crystallize at $81{ }^{\circ} \mathrm{C}$, which is $5{ }^{\circ} \mathrm{C}$ above the crystallization temperature of neat PB-1. Hence, iPP is capable of nucleating the PB-1 Form II crystals. The size of droplets is quite large in this case $\left(d_{n}=15.5 \mu \mathrm{m}\right)$.

As the content of PB-1 decreases to $30 \mathrm{wt} \%$ (Figure 3a), the crystallization peak corresponding to the PB-1 droplets develops a low-temperature shoulder at about 72 ${ }^{\circ} \mathrm{C}$. When the PB-1 is dispersed into smaller droplets $\left(d_{n} \approx 0.5 \mu \mathrm{m}\right)$, the crystallization exotherm shifts to approximately $72{ }^{\circ} \mathrm{C}$ and displays a single but broader peak (as compared to samples with 35-40 wt\%). In the subsequent DSC heating traces of Figure $3 \mathrm{~b}$, a new melting peak at lower temperatures appears at approximately $92^{\circ} \mathrm{C}$, indicative of the formation of Form $\mathrm{I}^{\prime}{ }^{47}$ Therefore, micrometer sized PB-1 droplets in blends with 25-30 wt\% i-PP apparently crystallize into Form I'. During the subsequent heating, those Form I' crystals melt and recrystallize into Form II crystals.

Additionally, when the $70 / 30$ sample was cooled at a slower rate $\left(0.5^{\circ} \mathrm{C} / \mathrm{min}\right)$, the bimodal exothermic peak was observed to split into two well-separated peaks (Figure S2), a typical feature of fractionated crystallization in immiscible polymer blends. ${ }^{5,6}$ The higher temperature exotherm is attributed to the crystallization of a droplet population nucleated by heterogeneities, since its peak crystallization temperature is identical to that of the PB-1 droplets of the $60 / 40$ or $65 / 35$ blends. The second exotherm, located at peak temperatures lower than that of neat PB-1, probably corresponds to a population of droplets with smaller sizes, which crystallize into Form $I^{\prime}$. Table 1 shows that the blends exhibit a wide dispersion of droplet sizes. 

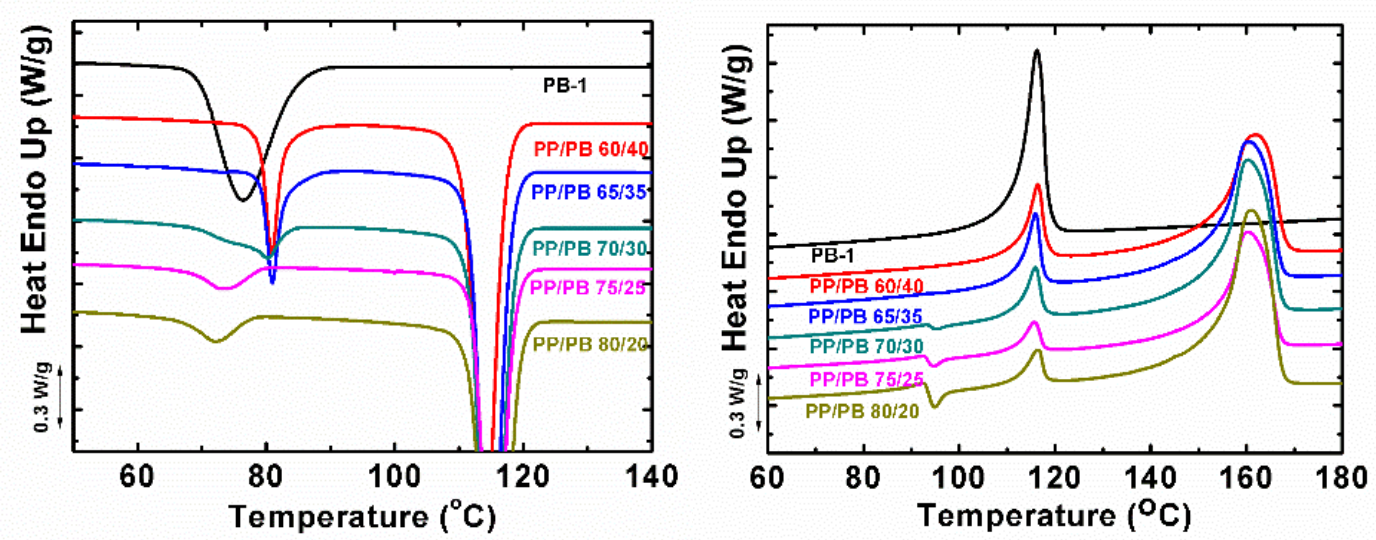

Figure 3. DSC cooling curves (a) and heating (b) curves of PP/PB-1 blends at $10^{\circ} \mathrm{C} / \mathrm{min}$.

Two samples, $70 / 30$ and $80 / 20$, were selected to perform in situ synchrotron WAXD experiments during cooling (Figure 4). The reflections observed at $2 \theta$ values of $11.4^{\circ}, 13.6^{\circ}, 14.9^{\circ}, 17.2^{\circ}$ and $17.6^{\circ}$ correspond to the (110), (040), (130), (131) and (041) crystallographic planes of $\alpha$-iPP, respectively. The reflections at $8.0^{\circ}, 13.9^{\circ}$ and $16.47^{\circ}$ belong to (110), (130), and $(220+211)$ crystal planes of PB-1 in Form I', respectively. The peaks at $9.58^{\circ}, 13.59^{\circ}$ and $14.71^{\circ}$ are instead assigned to (200), (220), and $(213+311)$ planes of Form II, respectively. Usually, the diffractions of $(110)_{\mathrm{I}^{\prime}}$ and $(200)_{\text {II }}$ are used to distinguish between the PB-1 polymorphs. ${ }^{32,45,52}$
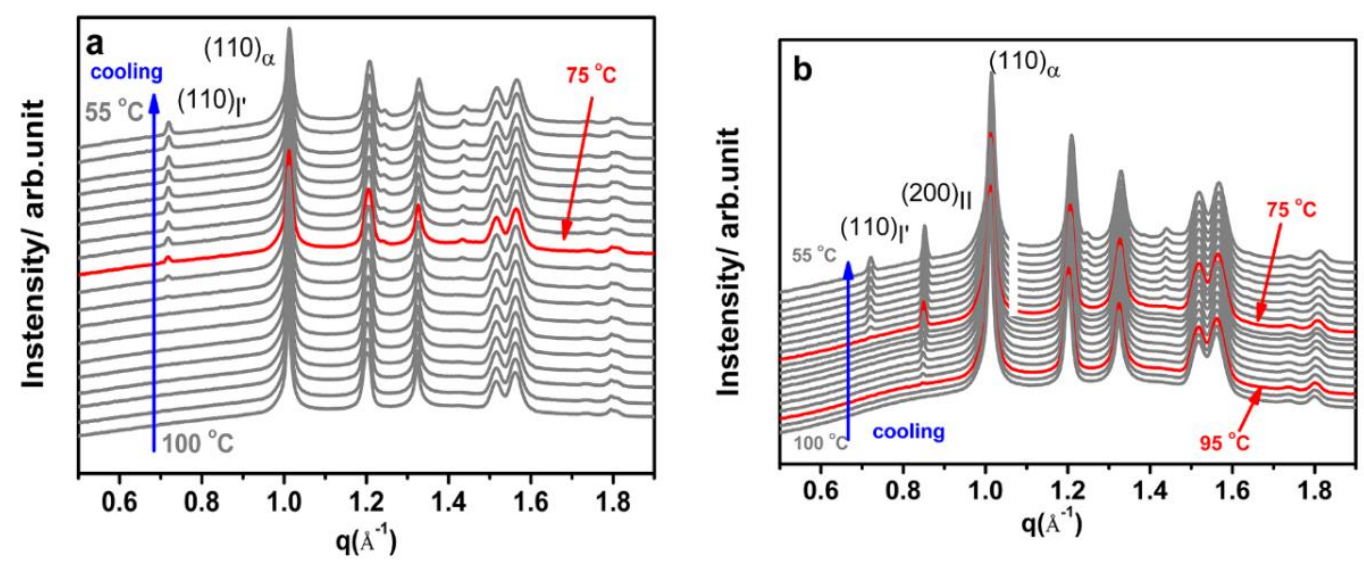

Figure 4. In situ WAXD patterns for PP/PB-1 blends 80/20 (a) and 70/30 (b) during cooling at $0.5^{\circ} \mathrm{C} / \mathrm{min}$.

Figure 4a shows that PB-1, within the $80 / 20$ blend, crystallizes exclusively into Form I' at a slow cooling rate of $0.5^{\circ} \mathrm{C} / \mathrm{min}$. On the other hand, both Form I' and II 
are formed when the content of PB-1 increases to $30 \mathrm{wt} \%$ in the blends (Figure 4b). It is interesting to note that Form II appears at a relatively high temperature $\left(95^{\circ} \mathrm{C}\right)$, while Form I' emerges at a lower temperature $\left(75^{\circ} \mathrm{C}\right)$. These observations support the interpretation of the origin of the two exothermic peaks in Figure S2, i.e., the higher temperature one corresponds to the crystallization of Form II, while the one at lower temperatures is related to the crystallization of PB-1 into Form I'. These results further suggest that two kinds of nucleation mechanisms are active in different droplet populations of PB-1 dispersed in iPP matrix, and that they favor the formation of two different crystalline phases.

\section{The dependence of crystal forms of PB-1 on crystallization temperature.}

After isothermal crystallization of the iPP matrix at $125{ }^{\circ} \mathrm{C}$, the samples were quenched to different temperatures in order to isothermally crystallize the PB-1 component in the blends. The WAXD profiles of PP/PB-1 80/20 after isothermal crystallization at different temperatures are shown in Figure 5, together with the relative amount of Form I' and Form II, as determined by the equations proposed by Turner-Jones ${ }^{35}$ :

$$
\begin{aligned}
& X_{I}=I_{(110)_{I^{\prime}}} / I_{(110)_{\alpha}} \\
& X_{I I}=I_{(200)_{I I}} / I_{(110)_{\alpha}}
\end{aligned}
$$

WAXD data confirmed the presence of Form I' at all the different crystallization temperatures. In particular, the content of Form I' increases gradually, with decreasing supercooling, while the amount of Form II correspondingly decreases. In other words, higher isothermal crystallization temperatures are beneficial for the formation of PB-1 Form I' in the PP/PB-1 blends. 

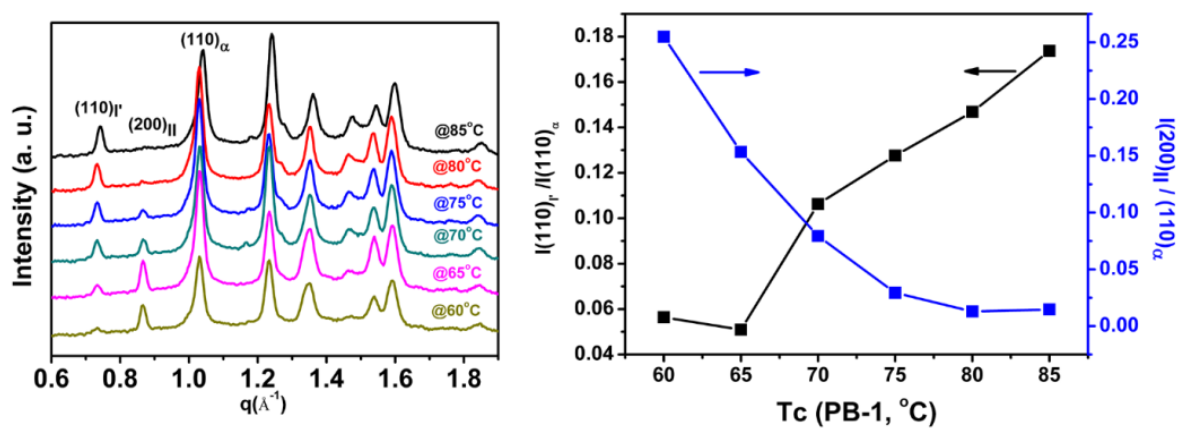

Figure 5. WAXD patterns (left) and relative content variation of Form I'and Form II (right) in 80/20 blend after isothermal crystallization at different temperatures. All samples were first isothermally crystallized at $125^{\circ} \mathrm{C}$ for $60 \mathrm{~min}$.

The DSC heating scans obtained after isothermal crystallization of the PB-1 dispersed phase in the same temperature range are reported in Figure 6. A single melting peak corresponding to Form I' was observed at higher crystallization temperatures, while the melting endotherm relative to Form II becomes more and more evident as the supercooling is increased. Form I' crystallized at 70 and $65{ }^{\circ} \mathrm{C}$ display the signature of melting and reorganization, probably due to the formation of low stability crystals. Furthermore, the melting temperature of Form I' increases with increasing isothermal crystallization temperature of PB-1, as expected.

According to Müller et al, ${ }^{1-3,5}$ if the polymer is in the bulk state or the size of the droplets is large enough, the existing heterogeneities can act as nucleants at relatively high temperature (lower supercooling). Otherwise, the heterogeneous nucleation of polymer droplets will be largely suppressed. In the current PP/PB-1 blends, it appears that two kinds of nucleation paths compete with each other, when PB-1 is dispersed into a large number of small droplets, and this competition depends on the nuclei supercooling/nucleation density. It is well known that a higher number of heterogeneities or nucleation sites get activated with decreasing undercooling, due to the supercooling dependent critical size of the crystallization nuclei. Considering the PB-1 droplets, a smaller amount of heterogeneous nuclei are supposed to be active at the highest crystallization temperature $\left(80-85{ }^{\circ} \mathrm{C}\right)$, as compared to higher supercoolings. Therefore, the observed crystallization temperature dependence of the 
polymorphic composition in the isothermally crystallized PB-1 droplets can be tentatively attributed to a different nucleation mechanism of the two polymorphs.

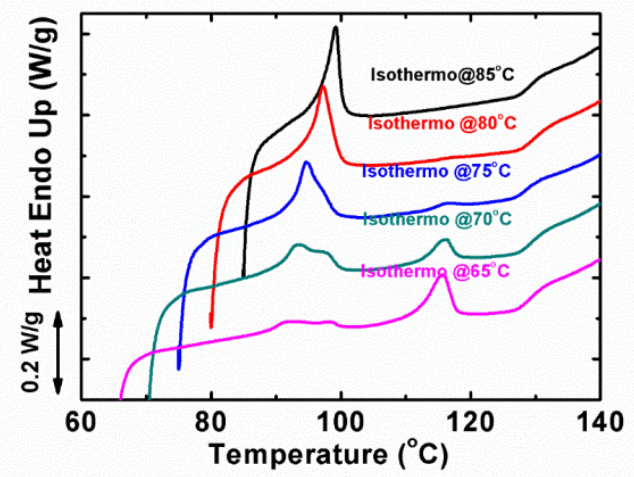

Figure 6. The heating process of $80 / 20$ sample at $10^{\circ} \mathrm{C} / \mathrm{min}$, after isothermal crystallization at the indicated different temperatures. The i-PP phase was first isothermally crystallized at $125^{\circ} \mathrm{C}$ for $60 \mathrm{~min}$.

We can assume that the crystallization of Form II starts from the original heterogeneities present in bulk PB-1, while Form I' is generated at the interface between PB-1 melt and solid iPP. The two nucleation paths are in competition: at high temperatures, the Form II nucleation ability of the present heterogeneities is less important in comparison to the iPP surface nucleation efficiency towards Form I'. As such, a substantial amount of Form I' can form and fill the droplet before Form II can develop to a large extent. The low amount (or low efficiency) of Form II nucleating impurities in the dispersed PB-1 droplets is also testified by the absence of Form II re-crystallization upon heating, after Form I' melting (see Figure 6, heating after crystallization at 80 and $85{ }^{\circ} \mathrm{C}$ ), contrary to what is commonly observed in bulk samples. On the other hand, at higher supercooling, Form II nucleation in the droplets containing impurities can occur more easily and profusely, due to the lowered energy barrier for nuclei formation, and thus compete again with the weakly Form I' nucleating iPP interface.

In order to support the above described competitive nucleation mechanism, the role of PB-1 droplets self-seeding and the dependence of the polymorphic crystallization kinetics on the specific interfacial area between the two polymers will be addressed 
below.

\section{The influence of active nuclei injection on the polymorphism of PB-1.}

Given the large concentration of PB-1 droplets in the 80/20 blend with iPP, it is reasonably deduced that the crystallization of PB-1 can be enhanced only when a comparable number of active heterogeneities per unit volume are introduced in the blend. ${ }^{6,27}$ The self-nucleation procedure is the most efficient way to induce a large quantity of active nuclei in a crystallizing polymer melt.

DSC curves for cooling and heating processes of the 80/20 blend self-nucleated at different temperatures are shown in Figure 7. Three self-nucleation domains can be identified (Domains I, II, III). ${ }^{43}$
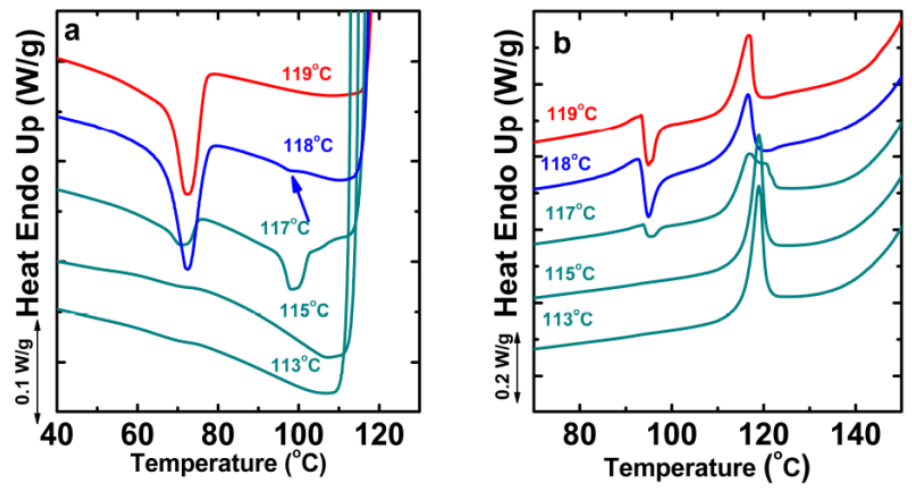

Figure 7. DSC cooling (a) and heating (b) curves of PP/PB-1 80/20 after self-nucleation at different Ts at $10^{\circ} \mathrm{C} / \mathrm{min}$. Red: Domain I, blue: Domain II, green: Domain III.

As the $T_{s}$ value decreases to $118{ }^{\circ} \mathrm{C}$ (Domain II) or $117{ }^{\circ} \mathrm{C}$ (Domain III), a small exothermic peak appears gradually upon cooling from the melt at around $98{ }^{\circ} \mathrm{C}$. The presence of two crystallization peaks is different from what is commonly observed in the self-nucleation test of bulk polymers, ${ }^{5}$ which may be ascribed to the small droplet size. Most probably, not all the MDs are self-nucleated at the specific temperature, since the dispersed droplets are effectively independent from one another. Therefore, self-nuclei only remain in some of the PB-1 droplets, at a given temperature. Similar results have been reported for the MDs crystallization within block copolymers and PS/PA6 blends system. ${ }^{9,27}$ The high temperature crystallization peak can be attributed 
to the development of Form II. In fact, the subsequent heating scans reveal a large decrease of the Form I' fraction. Self-nuclei are expected to be inside the droplets, and thus favor the development of Form II, which crystallizes faster at these superccolings, preventing interfacial nucleation of Form I' to occupy a large fraction of the domains.

\section{FT-IR study of crystallization kinetics of the different polymorphs:} interfacial nucleation mechanism of PB-1 Form I' crystals.

FT-IR is a sensitive tool to characterize polymer chain conformations. ${ }^{48}$ For PB-1, the typical absorption bands at $923 \mathrm{~cm}^{-1}$ and $905 \mathrm{~cm}^{-1}$ are usually adopted to differentiate the $3_{1}$ helices and $11_{3}$ helices belonging to Form $\mathrm{I}^{\prime}$ and Form II, respectively. ${ }^{44,45,53,54}$ Thus, the isothermal crystallization of the two polymorphs can be easily probed in situ via FT-IR spectroscopy.

Figure 8 reports the data acquired for the PP/PB 80/20 blend crystallized at $85{ }^{\circ} \mathrm{C}$. Both original and differential spectra, after subtraction of the initial spectrum at the beginning of the isotherm, are presented. While the increase of the absorbance of 923 $\mathrm{cm}^{-1}$ band in time is clearly deduced from the raw spectra, the variation of the 905 $\mathrm{cm}^{-1}$ band can hardly be distinguished, because of its overlap with the strong $899 \mathrm{~cm}^{-1}$ band of iPP (Figures 8a and 8c). ${ }^{48,55}$ In order to detect the increases in intensity of the $905 \mathrm{~cm}^{-1}$ band, relative to the crystallization of Form II, the corresponding differential spectra should be considered (Figure $8 \mathrm{~b}$ and $8 \mathrm{~d}$ ).

The absorbance of the $923 \mathrm{~cm}^{-1}$ and $905 \mathrm{~cm}^{-1}$ bands in the 80/20 sample at different temperatures versus time is shown in Figure S3. The variation of the $905 \mathrm{~cm}^{-1}$ band can be equilibrated within 3 min even at relatively high temperatures $\left(85^{\circ} \mathrm{C}\right)$, which means that the crystallization process of the relatively small amount of Form II is very fast and reaches saturation at the early stage of the process, while the formation of Form I' continues for more than 40 min. ${ }^{56,57}$ 

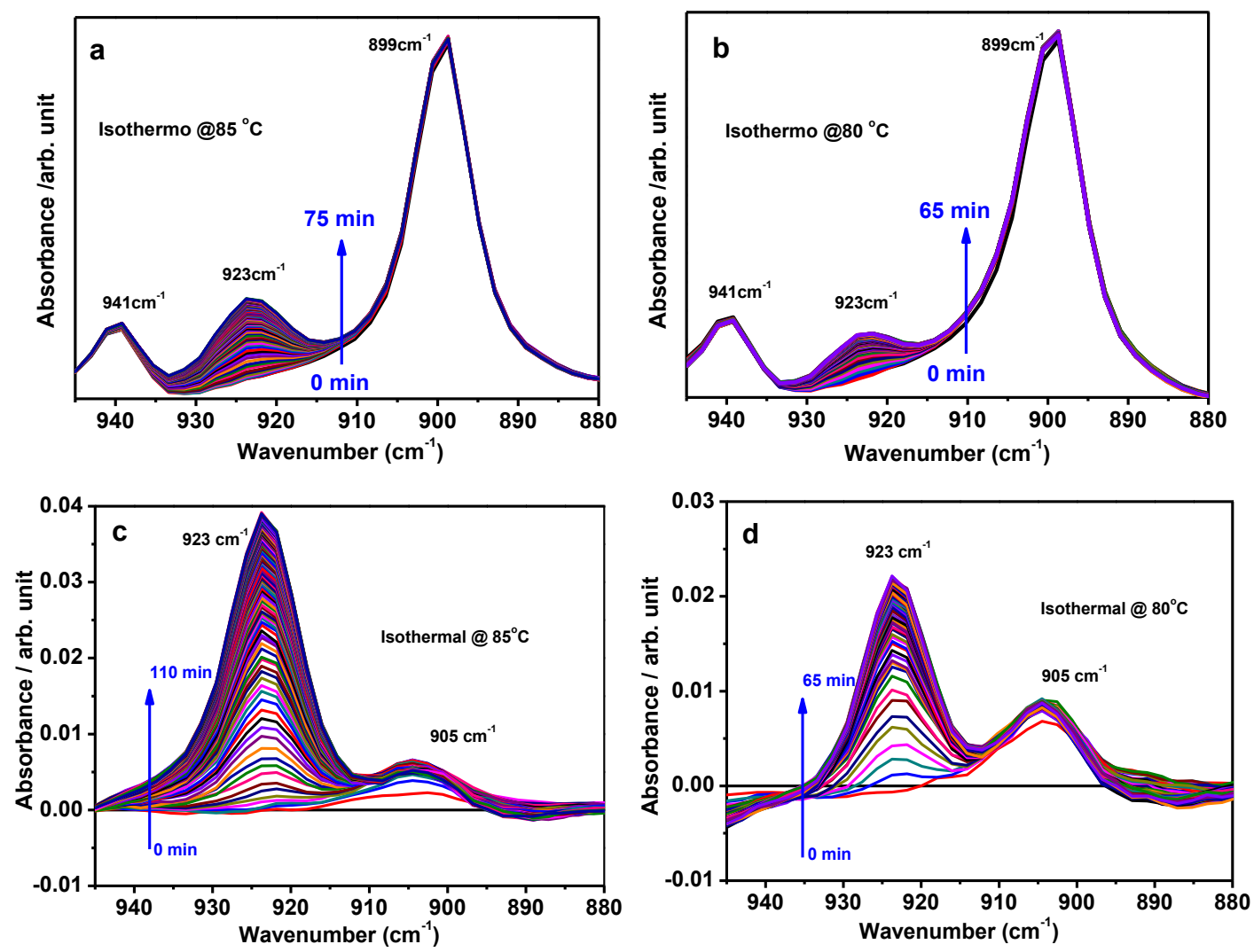

Figure 8. Time-resolved FT-IR spectra $(a, b)$ and the corresponding differential spectra $(c, d)$ of $80 / 20$ sample isothermally crystallized at $85^{\circ} \mathrm{C}$ and $80^{\circ} \mathrm{C}$. The spectra of the blends are stacked every $30 \mathrm{~s}$.

In order to investigate the effect of the polymer/polymer interface on the formation of Form I' crystals, the crystallization kinetics in blends with composition 70/30, $80 / 20$ and $90 / 10$ was studied. The absorbance of the $923 \mathrm{~cm}^{-1}$ band (Form $\mathrm{I}^{\prime}$ ) in 80/20 and 90/10 samples is summarized in Figures 9a and 9c. The crystallization rate of Form I' in the $90 / 10$ sample is distinctly faster than that of the $80 / 20$ sample, for both considered crystallization temperatures. This observation is difficult to be concealed with a crystallization kinetics dominated by nucleating heterogeneities dispersed in the droplets. Indeed, the higher amount of (smaller) droplets in the 90/10 blends as compared to the $80 / 20$ systems, should result in "cleaner" PB- 1 domains in the former case, leading to a slower crystallization kinetics for a given undercooling.

This situation has been in fact observed for the intensity variation of the $905 \mathrm{~cm}^{-1}$ band in the 70/30 and 80/20 samples (Figures $9 \mathrm{~b}$ and 9d), reflecting the crystallization rate of Form II. While the effect of composition is not noticeable in samples 
crystallized at $85^{\circ} \mathrm{C}$, at slightly lower supercooling (i.e., $\mathrm{Tc}=87^{\circ} \mathrm{C}$ ) the crystallization kinetics of Form II in the 70/30 sample becomes faster than that in the 80/20 blends. This is expected if one considers that with a larger volume of each dispersed domain, the probability of finding droplets containing Form II nucleating heterogeneities is higher.

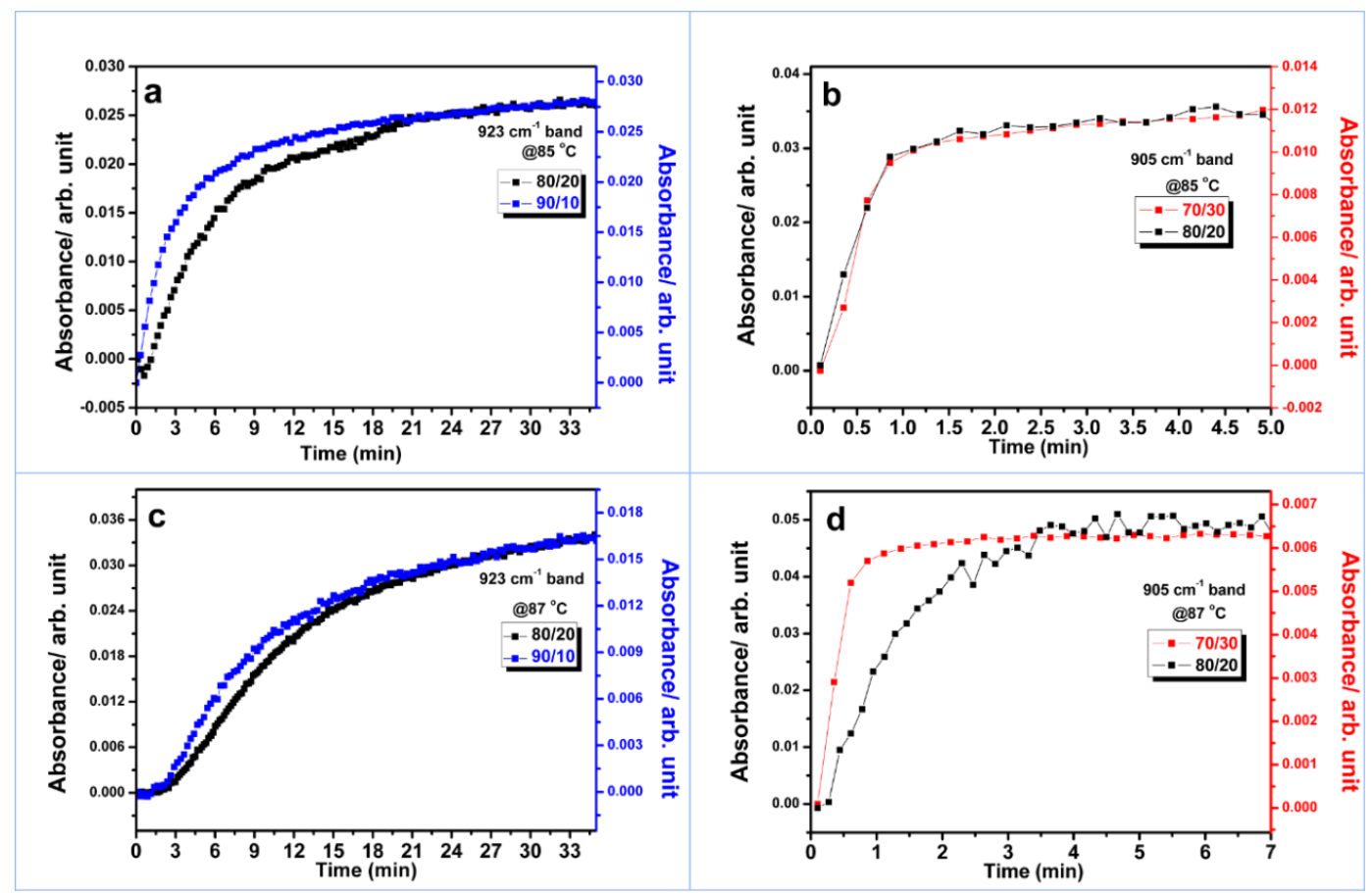

Figure 9. Variation of the absorbance of $923 \mathrm{~cm}^{-1}(a, c)$ and $905 \mathrm{~cm}^{-1}(b, d)$ band in $P P / P B$ blends as a function of crystallization time at the indicted crystallization temperatures.

On the other hand, the faster crystallization of Form I' in the blend with the lower amount of PB-1, supports the idea that the nucleation of this polymorph actually occurs at the interface between molten PB-1 droplet and solid iPP. In fact, on the basis of the morphological results summarized in Table 1 , the total content of the polymer/polymer interface per unit volume is $1.10 \times 10^{13} \mu^{2} / \mathrm{cm}^{3}$ and $2.90 \times 10^{14}$ $\mu \mathrm{m}^{2} / \mathrm{cm}^{3}$ for the $80 / 20$ and $90 / 10$ blends, respectively.

Considering the well-known similarities between iPP $\alpha$-phase and PB-1 Form I' crystals, which share the same $3_{1}$ helix and $c$-axis length of $6.5 \AA$, ${ }^{58}$ we can speculate that solid iPP surface can serve as an optimum substrate for crystallization of PB-1 trigonal phase. 


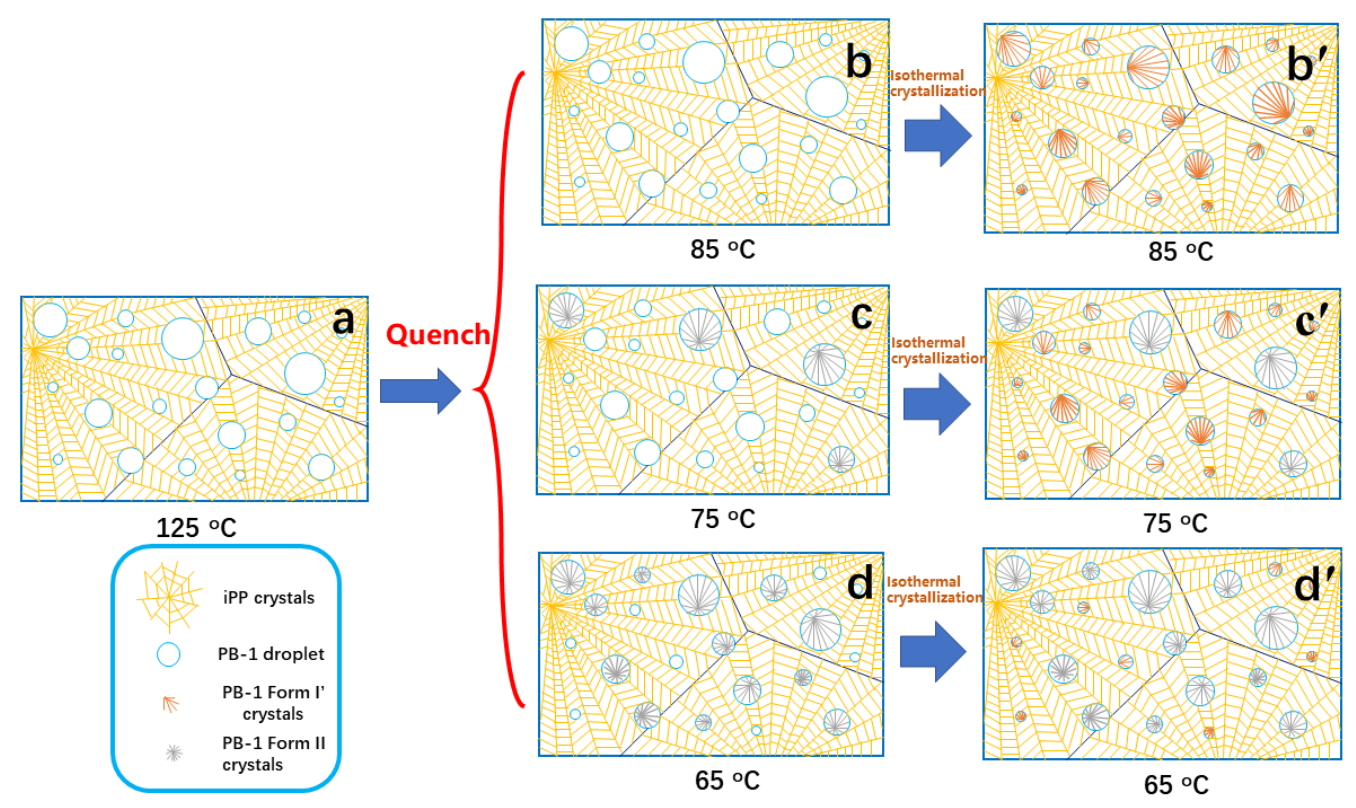

Figure 10. A simplified model describing the competition of Form II and Form I' crystallization in the PB-1 dispersed droplets within a blend with iPP matrix (i.e., 80/20 $i P P / P B-1$ blend).

On the basis of the above discussed FT-IR results, which corroborate the hypothesis of a different nucleation mechanism for the two polymorphs, the interpretation of the crystallization temperature-dependent polymorphism, highlighted in Figures 5 and 6 , can be described schematically in Figure 10.

When the sample crystallizes at relatively high temperatures (e.g., $85{ }^{\circ} \mathrm{C}$, Figures $10 \mathrm{~b}$ and $10 \mathrm{~b}^{\prime}$ ), nucleation of Form II on heterogeneities contained in the droplet is relatively slow, thus only a small number of droplets can give rise to the trigonal polymorph, while most of the droplets can be considered effectively "clean" from heterogeneous nuclei. In this situation, Form $\mathrm{I}^{\prime}$ nucleated at the droplet/matrix interface can grow even at a slow pace, until all the droplets are saturated.

With the decrease of $\mathrm{T}_{\mathrm{c}}\left(75^{\circ} \mathrm{C}\right.$, Figures $10 \mathrm{c}$ and $\left.10 \mathrm{c}^{\prime}\right)$, Form II nucleation on the present heterogeneities becomes faster and part of the droplets ensemble will be occupied by Form II crystals already at a very early stage. As such, Form I' can only grow in the remaining "clean" droplets. The neat result is an increment of the Form II fraction in the crystallized sample.

Upon further increase of the undercooling (Figures $10 \mathrm{~d}$ and $10 \mathrm{~d}^{\prime}$ ), only a minor 
amount of extremely "pure" (and small) droplets will develop into Form I', since Form II heterogeneous nucleation on impurities will be even faster, and most of the droplets with larger size will solidify in this modification.

\section{CONCLUSIONS}

The nucleation mechanism of PB-1 upon cooling from the melt drastically changes when it is dispersed in droplets within an iPP matrix. Our results have shown for the first time how as the droplet size is reduced, the formation of Form $\mathrm{I}^{\prime}$ is increasingly favored over its crystallization into the metastable Form II.

Form I' crystallizes faster (as indicated by our FT-IR experiments) when the content of PB-1 in the blend is lower, and the specific interfacial surface area of the droplets is larger. The opposite effect has been observed for the kinetics of the metastable Form II formation. As a consequence of the different kinetics, we postulate that the possible mechanism behind the interesting experimental observations made in this work is a competition between the heterogeneous nucleation of the droplets and the surface nucleation caused by the iPP matrix. The former induces the formation of Form II crystals while the latter Form I' crystals.

\section{AUTHOR INFORMATION}

\section{Corresponding Authors}

*E-mail: alejandrojesus.muller@ehu.eus, djwang@iccas.ac.cn.

\section{Notes}

The authors declare no competing financial interest.

\section{Acknowledgement}

Financial supports from the National Natural Science Foundation of China (Grant No. U1510207) and the Key Program for Coal-based Science and Technology of Shanxi Province (MH-2014-08) are gratefully acknowledged. GL is grateful for 
Youth Innovation Promotion Association, CAS (2015026). The synchrotron radiation measurements were carried out at Shanghai Synchrotron Radiation Facility (SSRF) BL14B1 beamline. Detailed information about beamline BL14B1 can be found in ref 59. ${ }^{59}$ ZW sincerely thanks the fruitful discussion with Prof. Charles Han at Shenzhen University and Prof. Yongfeng Men at Changchun Institute of Applied Chemistry, Chinese Academy of Science.

\section{REFERENCES}

(1) Müller, A. J.; Arnal, M. L.; Lorenzo, A. T., Crystallization in Nano-Confined Polymeric Systems. In Handbook of Polymer Crystallization, Piorkowska, E., Rutledge, G. C., Eds. John Wiley \& Sons, Inc: Hoboken, 2012; p347

(2) Michell, R. M.; Blaszczyk-Lezak, I.; Mijangos, C.; Müller, A. J. Confinement Effects on Polymer Crystallization: From Droplets to Alumina Nanopores. Polymer 2013, 54 (16), 4059-4077

(3) Michell, R. M.; Müller, A. J. Confined Crystallization of Polymeric Materials. Prog. Polym. Sci. 2016, 54-55, 183-213

(4) Frensch, H.; Harnischfeger, P.; Jungnickel, B. J. Fractionated Crystallization in Incompatible Polymer Blends. ACS Symposium Series 1989, 395, 101-125

(5) Michell, R. M.; Mugica, A.; Zubitur, M.; Müller, A. J., Self-Nucleation of Crystalline Phases Within Homopolymers, Polymer Blends, Copolymers, and Nanocomposites. In Polymer Crystallization I: From Chain Microstructure to Processing, Auriemma, F., Alfonso, G. C., DeRosa, C., Eds. Springer: Gewerbestrasse, 2017; Vol. 276, p215

(6) Arnal, M. L.; Matos, M. E.; Morales, R. A.; Santana, O. O.; Müller, A. J. Evaluation of the Fractionated Crystallization of Dispersed Polyolefins in a Polystyrene Matrix. Macromol. Chem. Phys. 1998, 199 (10), 2275-2288

(7) Cheng, S. Z. S., Metastable States in Phase Transitions of Polymers. In Phase Transitions in Polymers The Role of Metastable States, Cheng, S. Z. S., Ed. Elsevier: 2008; p77

(8) Huang, P.; Zhu, L.; Cheng, S. Z. D.; Ge, Q.; Quirk, R. P.; Thomas, E. L.; Lotz, B.; Hsiao, B. S.; Liu, L. Z.; Yeh, F. J. Crystal Orientation Changes in Two-dimensionally Confined Nanocylinders in a Poly(ethylene oxide)-b-polystyrene/polystyrene Blend. Macromolecules 2001, 34 (19), 6649-6657

(9) Müller, A. J.; Balsamo, V.; Arnal, M. L.; Jakob, T.; Schmalz, H.; Abetz, V. Homogeneous Nucleation and Fractionated Crystallization in Block Copolymers. Macromolecules 2002, 35 (8), 3048-3058

(10)Huang, P.; Zhu, L.; Guo, Y.; Ge, Q.; Jing, A. J.; Chen, W. Y.; Quirk, R. P.; Cheng, S. Z. D.; Thomas, E. L.; Lotz, B.; Hsiao, B. S.; Avila-Orta, C. A.; Sics, I. Confinement Size Effect on Crystal Orientation Changes of Poly(ethylene oxide) Blocks in Poly(ethylene oxide)-b-polystyrene Diblock Copolymers. Macromolecules 2004, 37 (10), 3689-3698 
(11) Huang, P.; Guo, Y.; Quirk, R. P.; Ruan, J.; Lotz, B.; Thomas, E. L.; Hsiao, B. S.; Avila-Orta, C. A.; Sics, I.; Cheng, S. Z. D. Comparison of Poly(ethylene oxide) Crystal Orientations and Crystallization Behaviors in Nano-confined Cylinders Constructed by a Poly (ethylene oxide)-b-polystyrene Diblock Copolymer and a Blend of Poly(ethylene oxide)-b-polystyrene and Polystyrene. Polymer 2006, 47 (15), 5457-5466

(12)Huang, P.; Zheng, J. X.; Leng, S.; Van Horn, R. M.; Jeong, K.-U.; Guo, Y.; Quirk, R. P.; Cheng, S. Z. D.; Lotz, B.; Thomas, E. L.; Hsiao, B. S. Poly(ethylene oxide) Crystal Orientation Changes in an Inverse Hexagonal Cylindrical Phase Morphology Constructed by a Poly(ethylene oxide)-block-polystyrene Diblock Copolymer. Macromolecules 2007, 40 (3), 526-534

(13)Loo, Y. L.; Register, R. A.; Ryan, A. J.; Dee, G. T. Polymer Crystallization Confined in One, Two, or Three Dimensions. Macromolecules 2001, 34 (26), 8968-8977

(14)Lorenzo, A. T.; Arnal, M. L.; Müller, A. J.; Boschetti-de-Fierro, A.; Abetz, V. Nucleation and Isothermal Crystallization of the Polyethylene Block within Diblock Copolymers Containing Polystyrene and Poly(ethylene-alt-propylene). Macromolecules 2007, 40 (14), 5023-5037

(15)Chung, T.-M.; Wang, T.-C.; Ho, R.-M.; Sun, Y.-S.; Ko, B.-T. Polymeric Crystallization under Nanoscale 2D Spatial Confinement. Macromolecules 2010, 43 (14), 6237-6240

(16)Kailas, L.; Vasilev, C.; Audinot, J.-N.; Migeon, H.-N.; Hobbs, J. K. A Real-Time Study of Homogeneous Nucleation, Growth, and Phase Transformations in Nanodroplets of Low Molecular Weight Isotactic Polypropylene Using AFM. Macromolecules 2007, 40 (20), 7223-7230

(17)Massa, M. V.; Carvalho, J. L.; Dalnoki-Veress, K. Confinement Effects in Polymer Crystal Nucleation from the Bulk to Few-Chain Systems. Phys. Rev. Lett. 2006, 97 (24), 247802-1

(18)Steinhart, M.; Wendorff, J. H.; Greiner, A.; Wehrspohn, R. B.; Nielsch, K.; Schilling, J.; Choi, J.; Gosele, U. Polymer Nanotubes by Wetting of Ordered Porous Templates. Science 2002, 296 (5575), 1997-1997

(19)Duran, H.; Steinhart, M.; Butt, H. J.; Floudas, G. From Heterogeneous to Homogeneous Nucleation of Isotactic Poly(propylene) Confined to Nanoporous Alumina. Nano Letters 2011, 11 (4), 1671-1675

(20)Guan, Y.; Liu, G. m; Ding, G. Q; Yang, T. Y.; Müller, A. J.; Wang, D. J. Enhanced Crystallization from the Glassy State of Poly(L-lactic acid) Confined in Anodic Alumina Oxide Nanopores. Macromolecules 2015, 48 (8), 2526-2533

(21)Suzuki, Y.; Duran, H.; Steinhart, M.; Butt, H. J.; Floudas, G. Homogeneous Crystallization and Local Dynamics of Poly(ethylene oxide) (PEO) Confined to Nanoporous Alumina. Soft Matter 2013, 9 (9), 2621-2628

(22)Santana, O. O.; Müller, A. J. Homogeneous Nucleation of the Dispersed Crystallisable Component of Immiscible Polymer Blends. Polym. Bull. 1994, 32 (4), 471-477

(23) Morales, R. A.; Arnal, M. L.; Müller, A. J. The Evaluation of the State of 
Dispersion in Immiscible Blends Where the Minor Phase Exhibits Fractionated Crystallization. Polym. Bull. 1995, 35 (3), 379-386

(24)Avella, M.; Martuscelli, E.; Raimo, M. The Fractionated Crystallization Phenomenon in Poly(3- hydroxybutyrate)/poly(ethylene oxide) Blends. Polymer 1993, 34 (15), 3234-3240

(25)Ikkala, O. T.; Holstimiettinen, R. M.; Seppala, J. Effects of Compatibilization on Fractionated Crystallization of PA6/ PP Blends. J. Appl. Polym. Sci. 1993, 49 (7), 1165-1174

(26)Tang, T.; Huang, B. T. Fractionated Crystallization in Polyolefins-Nylon 6 Blends. J. Appl. Polym. Sci. 1994, 53 (3), 355-360

(27)Tol, R. T.; Mathot, V. B. F.; Reynaers, H.; Goderis, B.; Groeninckx, G. Confined Crystallization Phenomena in Immiscible Polymer Blends with Dispersed Micro-and Nanometer Sized PA6 Droplets Part 4: Polymorphous Structure and (Meta)-Stability of PA6 Crystals formed in Different Temperature Regions. Polymer 2005, 46 (9), 2966-2977

(28)Tol, R. T.; Mathot, V. B. F.; Groeninckx, G. Confined Crystallization Phenomena in Immiscible Polymer Blends with Dispersed Micro- and Nanometer Sized PA6 Droplets, Part 2: Reactively Compatibilized PS/PA6 and (PPE/PS)/PA6 Blends. Polymer 2005, 46 (2), 383-396

(29)Tol, R. T.; Mathot, V. B. F.; Groeninckx, G. Confined Crystallization Phenomena in Immiscible Polymer Blends With Dispersed Micro- and Nanometer Sized PA6 Droplets, Part 1: Uncompatibilized PS/PA6, (PPE/PS)/PA6 and PPE/PA6 Blends. Polymer 2005, 46 (2), 369-382

(30)Tol, R. T.; Mathot, V. B. F.; Groeninckx, G. Confined Crystallization Phenomena in Immiscible Polymer Blends with Dispersed Micro- and Nanometer Sized PA6 Droplets, Part 3: Crystallization Kinetics and Crystallinity of Micro- and Nanometer Sized PA6 Droplets Crystallizing at High Supercoolings. Polymer 2005, 46 (9), 2955-2965

(31)Luciani, L.; Seppala, J.; Lofgren, B. Polybutene: Its Preparation, Properties and Challenges. Prog. Polym. Sci. 1988, 13 (1), 37-62

(32)Wang, Y.; Liu, P; Lu, Y; Men, Y. Mechanism of Polymorph Selection during Crystallization of Random Butene-1/Ethylene Copolymer. Chinese Journal of Polymer Science 2016, 34 (8), 1014-1020

(33)Natta, G.; Corradini, P.; Bassi, I. W. Crystal Structure of Isotactic Poly-alpha-Butene. Nuovo Cimento 1960, 1, 52-67

(34)Tashiro, K.; Hu, J.; Wang, H.; Hanesaka, M.; Saiani, A. Refinement of the Crystal Structures of Forms I and II of Isotactic Polybutene-1 and a Proposal of Phase Transition Mechanism between Them. Macromolecules. 2016, 49 (4), 1392-1404

(35)Jones, A. T. Polybutene-1 - Type II Crystalline Form. Polymer Letters 1963, 1, 455-456

(36)Holland, V. F.; Miller, R. L. Isotactic Polybutene-1 Single Crystals: Morphology. J. Appl. Phys. 1964, 35 (11), 3241-3248

(37)Lotz, B.; Thierry, A. Spherulite Morphology of Form III Isotactic Poly(1-butene). Macromolecules 2003, 36 (2), 286-290 
(38)Jiang, S. D.; Duan, Y. X.; Li, L.; Yan, D. D.; Chen, E. Q.; Yan, S. An AFM Study on the Structure and Melting Behavior of Melt-crystallized Isotactic Poly(1-butene). Polymer 2004, 45 (18), 6365-6374

(39)Qiao, Y. N.; Wang, Q.; Men, Y. F. Kinetics of Nucleation and Growth of Form II to I Polymorphic Transition in Polybutene-1 as Revealed by Stepwise Annealing. Macromolecules 2016, 49 (14), 5126-5136

(40)Cavallo, D.; Gardella, L.; Portale, G.; Müller, A. J.; Alfonso, G. C. Kinetics of Cross-Nucleation in Isotactic Poly(1-butene). Macromolecules 2014, 47 (2), 870-873

(41)Cavallo, D.; Gardella, L.; Portale, G.; Müller, A. J.; Alfonso, G. C. On Cross- and Self-nucleation in Seeded Crystallization of Isotactic Poly(1-butene). Polymer 2013, 54 (17), 4637-4644

(42)Cavallo, D.; Zhang, L.; Sics, I.; Alfonso, G. C.; Dumas, P.; Marco, C.; Ellis, G. The Morphology and Polymorphism of Self-nucleated Trigonal Isotactic Poly(1-butene) Studied by Synchrotron IR Microspectroscopy. CrystEngComm 2016, 18 (5), 816-828

(43)Cavallo, D.; Gardella, L.; Portale, G.; Müller, A. J.; Alfonso, G. C. Self-nucleation of Isotactic Poly(1-butene) in the Trigonal Modification. Polymer 2014, 55 (1), 137-142

(44)Su, F. M.; Li, X. Y.; Zhou, W. M.; Zhu, S. S.; Ji, Y. X.; Wang, Z.; Qi, Z. M.; Li, L. B. Direct Formation of Isotactic Poly(1-butene) Form I Crystal from Memorized Ordered Melt. Macromolecules 2013, 46 (18), 7399-7405

(45)Ji, Y.; Su, F.; Cui, K.; Huang, N.; Qi, Z.; Li, L. Mixing Assisted Direct Formation of Isotactic Poly(1-butene) Form I' Crystals from Blend Melt of Isotactic Poly(1-butene)/Polypropylene. Macromolecules. 2016, 49 (5), 1761-1769

(46)Zhang, B.; Yang, D. C.; Yan, S. Direct Formation of Form I Poly(1-butene) Single Crystals from Melt Crystallization in Ultrathin Films. J. Polym. Sci, Part B: Polym. Phys. 2002, 40 (23), 2641-2645

(47)Shieh, Y. T.; Lee, M. S.; Chen, S. A. Crystallization Behavior, Crystal Transformation, and Morphology of Polypropylene/polybutene-1 Blends. Polymer 2001, 42 (9), 4439-4448

(48)Jiang, Q. H.; Zhao, Y.; Zhang, C. B.; Yang, J.; Xu, Y. Z.; Wang, D. J. In-situ Investigation on the Structural Evolution of Mesomorphic Isotactic Polypropylene in a Continuous Heating Process. Polymer 2016, 105 (22), 133-143

(49)Cham, P. M.; Lee, T. H.; Marand, H. On the State of Miscibility of Isotactic Poly(propylene)/Isotactic Poly(1-butene) Blends: Competitive Liquid-Liquid Demixing and Crystallization Processes. Macromolecules 1994, 27 (15), 4263-4273

(50)Bartczak, Z.; Galeski, A.; Pracella, M. Spherulite Nucleation in Blends of Isotactic Polypropylene with Isotactic Poly(butene-1). J. Appl. Polym. Sci. 1994, 54 (10), 1513-1524

(51)White, J. L.; Yang, J., Miscibility and Characteristics of Polyolefin Blends. In Polyolefin Blends, Nwabunma, D., Kyu, T., Eds. John Wiley \& Sons, Inc: Hoboken, 2008; p40 
(52)De Rosa, C.; Auriemma, F.; de Ballesteros, O. R.; Esposito, F.; Laguzza, D.; Di Girolamo, R.; Resconi, L. Crystallization Properties and Polymorphic Behavior of Isotactic Poly(1-Butene) from Metallocene Catalysts: the Crystallization of Form I from the Melt. Macromolecules 2009, 42 (21), 8286-8297

(53)Shi, J. Y.; Wu, P. Y.; Li, L.; Liu, T.; Zhao, L. Crystalline Transformation of Isotactic Polybutene-1 in Supercritical CO2 Studied by in-situ Fourier Transform Infrared Spectroscopy. Polymer 2009, 50 (23), 5598-5604

(54)Luongo, J. P.; Salovey, R. Infrared Specctra of the Polybutene-1 Polymorphs. J. Polym. Sci, Part B: Polym. Lett. 1965, 3, 513-515

(55)Huang, M. M.; Dong, X.; Fu, D. S.; Huang, W. H.; Wu, L. M.; Huang, Q.; Wang, D. J. Effects of Ethylene Segments on the Crystallization and Tensile Properties of Biaxially Oriented Polypropylene. Acta Polymerica Sinica 2014, (4), 455-465

(56) Yamashita, M.; Kato, M. Surface Free Energies of Isotactic Polybutene-1 Tetragonal and Trigonal Crystals: the Role of Conformational Entropy of Side Chains. J. Appl. Cryst. 2007, 40, S558-S563

(57) Yamashita, M.; Takahashi, T. Melt Crystallization of Isotactic Polybutene-1 Trigonal Form: the Effect of Side Chain Entropy on Crystal Growth Kinetics. Polymer Journal 2008, 40 (10), 996-1004

(58)Bruckner, S.; Meille, S. V.; Petraccone, V.; Pirozzi, B. Polymorphism in Isotactic Polypropylene. Prog. Polym. Sci. 1991, 16 (2-3), 361-404

(59)Yang, T. Y.; Wen, W.; Yin, G. Z.; Li, X. L.; Gao, M.; Gu, Y. L.; Li, L.; Liu, Y.; Lin, H.; Zhang, X. M.; Zhao, B.; Liu, T. K.; Yang, Y. G.; Li, Z.; Zhou, X. T.; Gao, X. Y. Introduction of the X-ray diffraction beamline of SSRF. Nucl. Sci. Tech. 2015, 26 (2), $1-5$

\section{For Table of Contents use only}

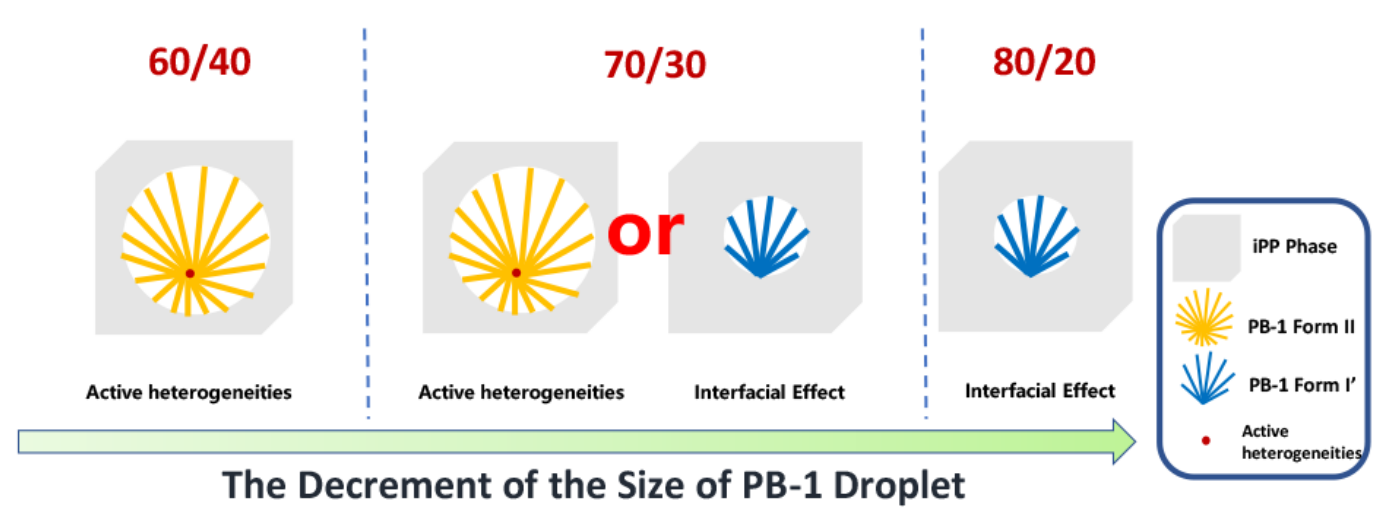

